\title{
Women's knowledge and associated factors on preconception care at Public Health Institution in Hawassa City, South Ethiopia
}

\author{
Andargachew Kassa ${ }^{*}$ and Zemenu Yohannes
}

\begin{abstract}
Objective: Preconception care is pivotal to improve pregnancy and birth outcome. It is vital for the future health of mother, her child and her family, which is routinely practice. The study aims to assess knowledge of preconception care and associated factors in post natal women at public health institution in Hawassa city, South Ethiopia.

Results: In this study $20 \%(95 \%$ Cl $16.9,23.1)$ of post natal women at public health institution had a good level of knowledge on preconception care. Women who have secondary and above education level, urban residence, and have at least one ANC contact had significantly higher odds of good level of knowledge on preconception care. The finding of this study showed that level of women's knowledge towards preconception care to be low compared to other studies. Having at least one ANC contact, urban residence and having secondary and above education are predictors of knowledge on preconception care. It shall be beneficial if the city health administration, regional and national health authorities work towards improving the knowledge of mothers towards preconception care as well as routine provision of preconception care in the health care system.
\end{abstract}

Keywords: Knowledge, Preconception care, Ethiopia

\section{Introduction}

Preconception care (PCC) is pivotal to improve pregnancy and birth outcome. It is vital for the future health of mother, her child and her family, preconception care (PCC) is used. Despite policy planners and stakeholders are given priority agenda for maternal and child health care, maternal and neonatal mortality reduction is not at the desired level $[1,2]$. Preconception health care hasn't become part of routine practice across the globe. In low income countries, the implementation of PCC is almost nil. Nevertheless in this region, there is higher maternal and neonatal death of which $90 \%$ are preventable [3-6].

Maternal and child health experts recommend that preconception health care is an essential intervention to modify biomedical, behavioural and social risks for better pregnancy and child birth outcome through risk assessment, health promotion, disease prevention and

\footnotetext{
*Correspondence: akandkassa@gmail.com

Department of Midwifery, College of Medicine and Health Sciences,

Hawassa University, Hawassa, Ethiopia
}

care provisions $[7,8]$. Preconception care $(\mathrm{PCC})$ is the provision of biomedical, behavioural and social health interventions to women and couples before conception and aims at improving their health status, and reducing behaviours and individual and environmental factors that contribute to deprive maternal and child health outcomes [9].

In 2015, an estimated 303,000 women died as a result of pregnancy and child birth related complications in the world, of which $99 \%$ occurred in low and middleincome countries, especially south Asia and sub-Saharan Africa. The frontline cause of maternal deaths globally are hemorrhage (27\%), pre-existing medical conditions (15\%), hypertension (14\%), sepsis (11\%), abortion (8\%), and other indirect causes (7\%) [10]. Under-five mortality in 2015 was 42.5 per 1000 live births [11, 12]. In Ethiopia maternal mortality ratio is estimated 412 deaths per 100,000 live births in 2016 and the under-five mortality at 67 per 1000 live birth in 2016 [13].

Preconception care is cardinal to alleviate different risk behaviours, exposures that affects conception, fetal 
development, and ultimately reduce subsequent adverse outcomes [14]. It is also important for different behavioural changes like maintaining normal body mass index, taking appropriate diet (daily vegetables and fruits), avoiding drinking alcohol, stop smoking, being away from hazardous area, and also attending to early a medical checkup to optimize maternal and neonatal health. For example, risk of neural tube defect can be lessened through supplementation of folic acid 3 months before conception. During the first 7 weeks of gestation (before 52 days of pregnancy) exposure to alcohol, tobacco and other drugs, lack of essential vitamins (e.g. folic acid) and workplace hazards can adversely affects pregnancy outcome and maternal and neonatal wellbeing $[15,16]$.

Knowledge of preconception care can be obtained from experience, health care providers, coffee ceremony (neighbour meeting to drink coffee and discuss any agenda during that time), family, reading books, newspapers, radio, television, and social media. Studies revealed that women who received pre-pregnancy care have more knowledge and often show risk alleviation behaviours [17].

Studies recommended that antenatal care should start before conception to alleviate bad obstetrics outcome. Maternal and child health planners, policy-makers and stakeholders should be cognizant of the values of PCC to attain the sustainable development goal (SDG) targets in relation to maternal, neonatal and child health. Therefore, evidence of knowledge and associated factors towards preconception care among mothers in Ethiopia is very rare. Hence, the aim of this study was to assess the level of knowledge and associated factors towards preconception care among mothers who gave birth at public health institution in Hawassa city, Southern Ethiopia.

\section{Main text}

\section{Methods and materials}

\section{Study design and setting}

Health institution based cross sectional study was carried out from March 01-30, 2017 among mothers who gave birth at public health institution in Hawassa city. Hawassa is administrative city of Southern Nations, Nationalities and Peoples Regional State (SNNPRS) and located $275 \mathrm{~km}$ South from Addis Ababa. According to the 2017 City Health Department estimation report, there were 359,358 people living in Hawassa. The city has 8 sub city and 32 kebeles, which have 83 public and private health institutions. These are one public referral and teaching hospital, one public general hospital, 4 private primary hospitals, 9 public health centers, 17 health posts and 51 private clinics. During the study period, there were 1452 health professionals working in the randomly selected public health institutions of the city.

Hawassa University referral and teaching hospital is the largest hospital in southern Ethiopia with more than 300 beds which renders service in the region and the neighbouring region. The outpatient department consists of 17 rooms and inpatient service which consisted of 5 main departments. The average number of patient flow at the OPD was more than 200 people per day. Hawassa University referral and teaching hospital and Adare general hospital are public health hospitals providing comprehensive essential obstetric care in the City. The remaining 9 PHC are giving basic essential obstetric care. In the past 6 months of the year 2016, there were a total of 4780 deliveries reported from Hawassa University referral and teaching hospital (2073), Adare general hospital (2022), Adare health center (313), Millennium health center (311), and Tilte health center (61).

The source populations were all pregnant women who live in the Hawassa City Administration. Whereas, the study populations were those who gave birth during the study period at public health institution in Hawassa city.

Sample size was determined using single population proportion formula with confidence interval 95\%, p-valve 0.5 , margin of error $(\alpha=0.05)$, a design effect of 2 and $10 \%$ non-response rate. The total sample size is 580 .

Five public health institutions were selected using simple random sampling technique. Multistage sampling technique was used to select a total of 580 study participants using random sampling methods. The calculated sampling interval $(\mathrm{K})$ was 1.2 . Based on the finding we consecutively recruited the study subject's. The samples were taken proportionate to the number of expected deliveries from each selected PHIs. All participants included in the study were all consented to participate wilfully in the study.

The questionnaire was developed by reviewing different existing literatures. First developed in English and translated into Amharic and then back to English to check the accuracy. The socio-demographic factors are; age, parity, educational status, religion, occupation, partner's occupation, and residence, gravidity, antenatal care attendee, gestation, previous history of adverse pregnancy outcomes such as history of baby with macrosomia and also history of pregnancy induced hypertension in the previous pregnancy, whereas dependent variable was the 'Women's Knowledge about PCH/C".

Before the actual data collection, the questionnaire was tested on $10 \%$ care in post natal women at public health institutions in Shashemene city, which is $20 \mathrm{~km}$ away from Hawassa city.

Operational definitions: Women's knowledge about preconception health and care was measured based on 
the individual study participant's correct response of 17 items measuring their knowledge about PCC. Each question had one correct answer those who scored 50\% and above of the items are labelled as women with "good $\mathrm{PCH} / \mathrm{C}$ knowledge" whereas those remaining categorized as women with poor PCC knowledge.

Data were collected by 5 BSC female midwives and 5 BSC female nurses after 1-day training about informed consent, techniques of interviewing, and data collection procedures. Two health officers were assigned to supervisors for the data collectors.

\section{Statistical analysis}

The data were entered and cleaned using SPSS version 20 for analysis. Those factors found with their $P$ value $\leq 0.20$ in the bi-variable logistic regression model were fitted into the multivariable logistic regression model to control the effect of confounding variables. Multivariable analysis was carried out to evaluate the independent effect of each covariate on 'good $\mathrm{PCH} / \mathrm{C}$ knowledge' by controlling the effect of others. P value $<0.05$ is taken as statistically significant. For further analysis, descriptive statistics like frequencies and cross tabulation were performed. Tables and figure were used to present the findings of the study.

\section{Result}

\section{Socio demographic characteristics}

This study included 580 women who gave birth in public health institutions of Hawassa city. Most of the study participants were ethnic Sidama (40\%), followed by Oromo (19.8\%), and Wolayita (18.3\%). One-fifth (20\%) of the women never attended formal education and more than half $(56 \%)$ attended primary level of education. About

Table 1 Socio-demographic characteristics of women who gave birth in public health institutions of Hawassa ( $\mathrm{n}=580$ ), Northern Ethiopia 2017

\begin{tabular}{|c|c|c|c|c|}
\hline S. N. & Variables & Categories & Frequency(n) & Percent (\%) \\
\hline \multirow[t]{3}{*}{1} & Age of the mother & $<20$ years & 45 & 8 \\
\hline & & $20-34$ years & 492 & 84.6 \\
\hline & & $35-49$ years & 43 & 7.4 \\
\hline \multirow[t]{2}{*}{2} & Marital status & Married & 560 & 96.6 \\
\hline & & Single & 20 & 3.4 \\
\hline \multirow[t]{6}{*}{3} & Ethnicity & Sidama & 232 & 40 \\
\hline & & Amhara & 42 & 7.2 \\
\hline & & Gurage & 46 & 7.9 \\
\hline & & Oromo & 115 & 19.8 \\
\hline & & Wolayta & 106 & 18.3 \\
\hline & & Silte & 39 & 6.8 \\
\hline \multirow[t]{4}{*}{4} & Women's education status & No formal education & 110 & 19 \\
\hline & & Primary education (1-8 grade) & 325 & 56 \\
\hline & & Secondary education (9-12 grade) & 97 & 16.7 \\
\hline & & Tertiary (college or university) & 48 & 8.3 \\
\hline \multirow[t]{5}{*}{5} & Occupation & Housewife & 399 & 68.8 \\
\hline & & Private business & 87 & 15 \\
\hline & & Daily worker & 14 & 2.4 \\
\hline & & Salaried employed & 61 & 10.5 \\
\hline & & Student & 19 & 3.3 \\
\hline \multirow[t]{4}{*}{6} & Monthly income & $<1000$ ETB & 174 & 30 \\
\hline & & $1001-2000$ ETB & 119 & 20 \\
\hline & & 2001-3675 ETB & 142 & 25 \\
\hline & & $>3675$ ETB & 145 & 25 \\
\hline \multirow[t]{3}{*}{7} & Total family size & $<5$ & 456 & 78.6 \\
\hline & & 6-May & 89 & 15.4 \\
\hline & & $>6$ & 35 & 6 \\
\hline \multirow[t]{2}{*}{8} & Residence & Urban & 375 & 64.7 \\
\hline & & Rural & 205 & 35.3 \\
\hline
\end{tabular}


two-third (64.7\%) of participants were urban residents (Table 1).

\section{Prevalence of PCC knowledge}

In this study $20 \%, 95 \%$ CI $(16.9,23.1)$ has good knowledge about preconception care among women who gave birth in the public health institutions of Hawassa city administration (Fig. 1).

\section{Information about preconception health and care}

Nearly all of the study participants reported that they never received information regarding preconception care. About one-third 182 (31.4\%) of the study participants reported that they get advise on diet/nutrition prior to pregnancy, but only $9(1.6 \%)$ of the study participants reported they were counselled about preconception folic acid supplementation. The other reported preconception care was advice about avoidance of alcohol. This was a case reported by only one participant $(0.2 \%)$.

The analysis of this study also denoted, next to health professionals, mass media (Television and radio) (4\%), Flier or brochures $(1.6 \%)$, family or friend $(2.2 \%)$, school or university $(1.0 \%)$, and internet $(0.2 \%)$ as source of information preconception health care.

\section{Factors associated with women's knowledge about preconception care}

Results of the multivariable logistic regression showed that women who attended to at least one antenatal care clinic contact were four times knowledgeable about preconception care than counterpart $(\mathrm{AOR}=4.0,95 \%$ CI 1.1-12.6). Women who live in urban were two times knowledgeable about preconception care than counterpart $(\mathrm{AOR}=2.0,95 \% \mathrm{CI} 1.1-3.3)$. Those women who attended high school and above were by two times knowledgeable about PCC than their counterparts $(\mathrm{AOR}=2.0,95 \% \mathrm{CI} 1.1-3.3)$ (Table 2$)$.

\section{Discussion}

Preconception care is a key means for reducing and preventing maternal and child morbidity and mortality. Nevertheless, it is not well practice in developing countries. This study showed that overall level of knowledge on preconception care among mothers who gave birth at public health institution in Hawassa city is $20 \%$. This finding is higher than the study done in Nigeria (2.5\%) [18], Iran (10.4\%) [19] and Sudan (11.1\%) [20]. The higher level of knowledge noticed in this study might be due to the fact that the current study took place immediately after the mothers gave birth.

On the other hand, it is lower than compared to other study done in Amhara region, northern Ethiopia (27.5\%) [21], Saudi Arabia (37.9\%) [22], United Arab Emirates (46.4\%) [23], and Turkey (46.3\%) [24], in Kelantan, Malaysia (51.9\% [25], Qatar (53.7\%) [26], Canada 70\% [27], British Colombia 71\% [28], in the USA among low income Mexican-American group (76\%) [29], Saudi Arabia (84.6\%) [30], Jordan (85\%) [31].

The low knowledge identified level in this study might be due to the low socioeconomic conditions, due to low media coverage regarding preconception care, low habit of check-up for ANC, the low attention given to preconception care implementation by the health industry across the country, and lack of preconception clinic at health institution level.

In this study there was association of level of knowledge on preconception care with factors such as, level of education, place of residence, and ANC contact. Women who had above secondary education level had two times higher odds to have good level of knowledge on preconception care. This finding is consistent with the study done Ethiopia, Nigeria, Iran, Sudan, USA, Netherlands and Sri Lanka $[18,20-22,29,32,33]$. This may be explained as the women's educational status is increase, their health

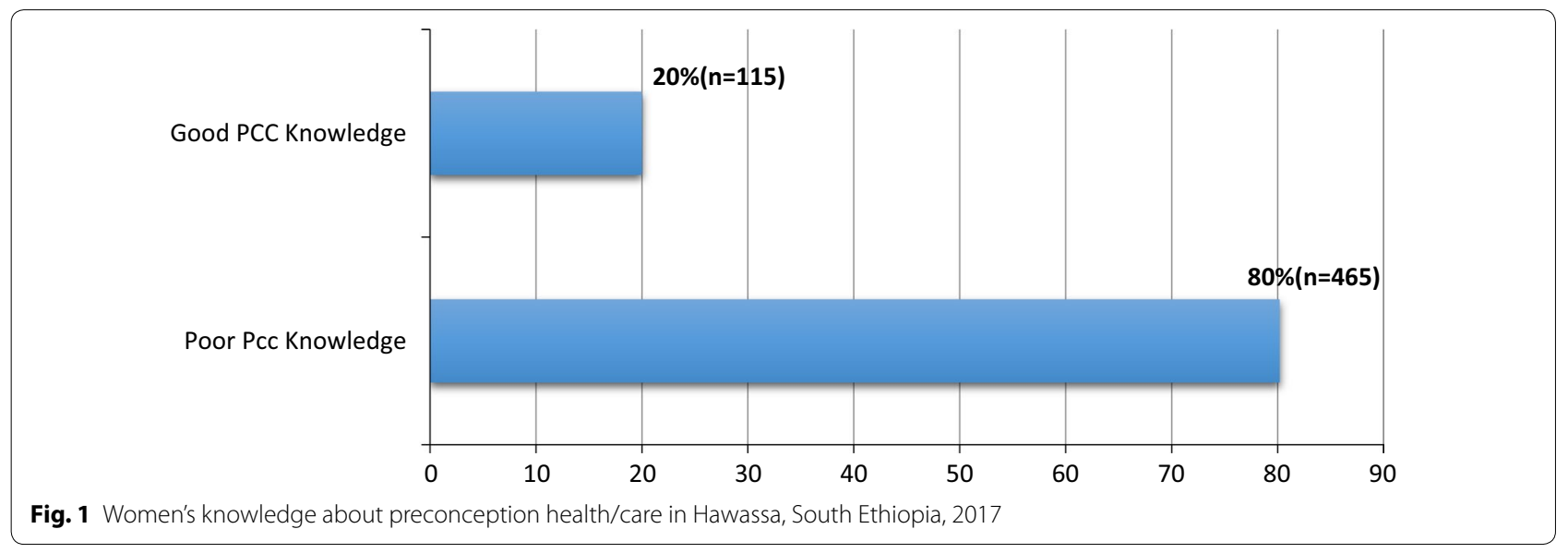


Table 2 Bivariate and multivariate analysis depicting factors associated with good preconception health/care knowledge among women giving birth in Hawassa, Ethiopia 2017

\begin{tabular}{|c|c|c|c|c|c|}
\hline & & \multicolumn{2}{|c|}{ Client's preconception knowledge } & \multirow[t]{2}{*}{$\mathrm{COR}, 95 \% \mathrm{Cl}$} & \multirow[t]{2}{*}{$\mathrm{AOR}, 95 \% \mathrm{Cl}$} \\
\hline & & Poor PCC knowledge & Good PCC knowledge & & \\
\hline \multirow[t]{2}{*}{ Women's educational status } & Elementary and below & $372(64 \%)$ & $63(11 \%)$ & 1 & 1 \\
\hline & High school and above & $93(16 \%)$ & $52(9 \%)$ & $3.3(2.1-5.1)^{* * *}$ & $2.0(1.1-3.3)^{*}$ \\
\hline \multirow[t]{2}{*}{ Husband's educational Status } & Elementary and below & $295(51 \%)$ & $47(8.1 \%)$ & 1 & 1 \\
\hline & High school and above & $170(29.3 \%)$ & $68(11.7 \%)$ & $2.5(1.7-3.8)^{* * *}$ & $1.3(0.7-2.3)$ \\
\hline \multirow[t]{4}{*}{ Monthly house hold income } & $\leq 1000.0$ birr & $147(25.4 \%)$ & $27(5.0 \%)$ & 1 & 1 \\
\hline & 1001.0-2000.0 birr & $98(16.9 \%)$ & $21(3.6 \%)$ & $1.2(0.6-2.2)$ & $1.4(0.8-2.9)$ \\
\hline & 2001.0-3675.0 birr & $117(20.2 \%)$ & $25(4.3 \%)$ & $1.2(0.6-2.1)$ & $1.1(0.6-2.1)$ \\
\hline & $\geq 3676.0$ birr & $103(17.8 \%)$ & $42(7.2 \%)$ & $2.2(1.3-3.9)^{*}$ & $1.5(0.8-2.9)$ \\
\hline \multirow[t]{2}{*}{ Women's place of residence } & Rural & $183(31.6 \%)$ & $22(3.8 \%)$ & 1 & 1 \\
\hline & Urban & $282(48.6 \%)$ & $93(16.0 \%)$ & $2.7(1.7-4.5)^{* * *}$ & $2.0(1.1-3.3)^{*}$ \\
\hline \multirow[t]{2}{*}{ Attended ANC for at least one visit } & Not attended ANC & $56(9.7 \%)$ & $3(0.5 \%)$ & 1 & 1 \\
\hline & Attended at least one ANC visit & 409 (70.5\%) & $112(19.3 \%)$ & $5.1(1.6-16.6)^{*}$ & $4.0(1.1-12.6)^{*}$ \\
\hline \multirow{2}{*}{$\begin{array}{l}\mathrm{Hx}^{\mathrm{f}} \text { of previous infant with mac- } \\
\text { rosomia }\end{array}$} & No history & $414(71.4 \%)$ & 109 (18.8\%) & 1 & 1 \\
\hline & Yes & $51(8.8 \%)$ & $6(1.0 \%$ & $0.4(0.9-1.1)$ & $0.4(0.2-1.0)$ \\
\hline \multirow{2}{*}{$\begin{array}{l}\text { Hx of pregnancy Induced Hyper- } \\
\text { tension }\end{array}$} & No & $452(77.9 \%)$ & $107(18.5 \%)$ & 1 & 1 \\
\hline & Yes & $13(2.2 \%)$ & $8(1.4 \%)$ & $2.6(1.1-6.4)^{*}$ & $1.7(0.6-4.4)$ \\
\hline
\end{tabular}

$\mathrm{Hx}^{f}$ : history

${ }^{*} \mathrm{p}<0.05,{ }^{* *} \mathrm{p}<0.01$ and ${ }^{* * *} \mathrm{p}<0.001$

seeking behabour regarding preconception care will also increase. The more educated women might be eager to know about her own health status, and risks factors leading to ill health. These group of women do have better complication readiness plans. The more educated women might have interest to ask, read, listen, and watch any information sources related to her wellbeing.

Women who live in urban were two times higher odds to have good level of knowledge on preconception care than rural residents. This inconsistency is probably due to the fact that residents living in urban area might have better access to media and health institution. Women who attended at least one ANC contact had by four times higher odds to have good level of knowledge on preconception care. During ANC contact, women are informed about their health status, ways of disease prevention and health promotion, and birth preparedness and complication readiness.

\section{Conclusion}

The finding of this study showed that level of women's knowledge towards preconception care to be low compared to other studies. Having at least one ANC contact, urban residence and having secondary and above education are predictors of good level of knowledge on preconception care. It would be beneficial if the city health administration, regional and national health authorities work towards improving the knowledge of mothers towards preconception care as well as routine provision of preconception care in the health care system.

\section{Limitation}

One possible limitation of this study is the fact that it didn't include the husbands or spouses of the women. Results could also be to some extent affected by social desirability biases.

\section{Abbreviations \\ ANC: antenatal care; AOR: adjusted odds ratio; BEmONC: basic emergency obstetrics and new-born care.}

\section{Authors' contributions}

AK conceived of and designed the study, participated in data collection, analysed the data and drafted the paper. ZY and AK critically reviewed the study protocol, participated in data acquisition and analysis and reviewed the draft manuscript. Both authors read and approved the final manuscript.

\section{Acknowledgements}

We are very grateful thankful to all mothers who participated in this study for their commitment in responding to our interviews. Hawassa city administration health office and public health institution for their assistance and permission to undertake the research. 


\section{Competent interests}

The authors declare that they have no competing interests.

\section{Availability of data and materials}

All data on which this article is based are included within the article.

\section{Consent for publication}

Not applicable.

\section{Ethics approval and consent to participate}

Ethical clearance was obtained from Institution review board (IRB) of College of Medicine and Health Sciences (Ref No IRB/068/09). A letter of official support was taken to concerned facilities. Finally, each participant gave their informed verbal consent or parents and/or guardians provided consent on behalf of their new-born babies. Confidentiality was assured by making the questionnaire anonymous.

\section{Funding and sponsorship}

This research was funded by Hawassa University.

\section{Publisher's Note}

Springer Nature remains neutral with regard to jurisdictional claims in published maps and institutional affiliations.

Received: 5 October 2018 Accepted: 23 November 2018 Published online: 28 November 2018

\section{References}

1. Olayinka OA, Achi OT, Amos AO, Chiedu EM. Awareness and barriers to utilization of maternal health care services among reproductive women in Amassoma community, Bayelsa State. Int J Nurs Midwifery. 2014;6(1):10-5.

2. Nitert MD, Barrett H, de Jersey S, Matusiak K, Mclntyre H, Callaway L. Preconception care and barriers to addressing overweight and obesity: a focus on weight loss advice and weight loss strategies. In: Hollins-Martin C, van den Akker O, Martin C, Preedy VR (eds) Handbook of diet and nutrition in the menstrual cycle, periconception and fertility. Wageningen, Netherlands: Wageningen Academic Publishers; 2014. p. 568. https://doi. org/10.3920/978-90-8686-767-7

3. Boulet SL, Parker C, Atrash H. Preconception care in international settings. Matern Child Health J. 2006;10(1):29-35.

4. Ebrahim SH, Lo SS-T, Zhuo J, Han J-Y, Delvoye P, Zhu L. Models of preconception care implementation in selected countries. Matern Child Health J. 2006;10(1):37-42.

5. Ezegwui H, Dim C, Dim N, Ikeme A. Preconception care in south eastern Nigeria. J Obstet Gynaecol. 2008;28(8):765-8.

6. Frey KA, Files JA. Preconception healthcare: what women know and believe. Matern Child Health J. 2006;10(1):73-7.

7. Moos M-K. From concept to practice: reflections on the preconception health agenda. J Womens Health. 2010;19(3):561-7.

8. Curtis MG. Preconception care: clinical and policy implications of the preconception agenda. JCOM. 2010;17(4):30-8.

9. Organization WH. Preconception care: maximizing the gains for maternal and child health. Geneva: World Health Organization; 2013.

10. Black R, Laxminarayan $R$, Temmerman M, Walker N. Disease control priorities, (Volume 2): reproductive, maternal, newborn, and child health. The World Bank; 2016.

11. Alkema L, Chou D, Hogan D, Zhang S, Moller A-B, Gemmill A, et al. Global, regional, and national levels and trends in maternal mortality between 1990 and 2015, with scenario-based projections to 2030: a systematic analysis by the UN Maternal Mortality Estimation Inter-Agency Group. Lancet. 2016;387(10017):462-74.

12. You D, Hug L, Ejdemyr S, Idele P, Hogan D, Mathers C, et al. Global, regional, and national levels and trends in under-5 mortality between
1990 and 2015, with scenario-based projections to 2030: a systematic analysis by the UN Inter-agency Group for Child Mortality Estimation. Lancet. 2015;386(10010):2275-86.

13. Central Statistical Agency (CSA) [Ethiopia], ICF. Ethiopia Demographic and Health Survey 2016. Addis Ababa, Ethiopia, and Rockville, Maryland, USA: CSA and ICF; 2016.

14. Hood JR, Parker C, Atrash HK. Recommendations to improve preconception health and health care: strategies for implementation. J Womens Health. 2007:16(4):454-7.

15. Heyes T, Long S, Mathers N. Preconception care: practice and beliefs of primary care workers. Fam Pract. 2004;21(1):22-7.

16. James T. Preconception/inter-conception caretraining curriculum. Illions department of human services. 2015.

17. Elsinga J, de Jong-Potjer LC, van der Pal-de KM, le Cessie S, Assendelft WJ, Buitendijk SE. The effect of preconception counselling on lifestyle and other behaviour before and during pregnancy. Womens Health Issues. 2008;18(6):S117-25

18. Lawal TA, Adeleye AO. Determinants of folic acid intake during preconception and in early pregnancy by mothers in Ibadan, Nigeria. Pan Afr Med J. 2014:19:113.

19. Ghaffari F, Jahani Shourab N, Jafarnejad F, Esmaily H. Application of Donabedian quality-of-care framework to assess the outcomes of preconception care in urban health centers, Mashhad, Iran in 2012. J Midwifery Reprod Health. 2014;2(1):50-9.

20. Ahmed K, Saeed A, Alawad A. Knowledge, attitude and practice of preconception care among Sudanese women in reproductive age about rheumatic heart disease. Int J Public Health. 2015;3(5):223-7.

21. Ayalew Y, Mulat A, Dile M, Simegn A. Women's knowledge and associated factors in preconception care in adet, west gojjam, northwest Ethiopia: a community based cross sectional study. Reprod Health. 2017;14(1):15.

22. Madanat AY, Sheshah EA. Preconception care in Saudi women with diabetes mellitus. J Fam Community Med. 2016;23(2):109.

23. Abdulrazzaq YM, Al-Gazali LI, Bener A, Hossein M, Verghese M, Dawodu A, et al. Folic acid awareness and intake survey in the United Arab Emirates. Reprod Toxicol. 2003;17(2):171-6.

24. Baykan Z, Öztürk A, Poyrazoğlu S, Gün İ. Awareness, knowledge, and use of folic acid among women: a study from Turkey. Arch Gynecol Obstet. 2011;283(6):1249-53

25. Kasim R, Draman N, Abdul Kadir AA, Muhamad R. Knowledge, attitudes and practice of preconception care among women attending maternal health clinic in Kelantan. Educ Med J. 2016;8(4):57-68. https://doi. org/10.5959/eimj.v8i4.475.

26. Bener A, Al Maadid MG, Al-Bast DA, Al-Marri S. Maternal knowledge, attitude and practice on folic acid intake among Arabian Qatari women. Reprod Toxicol. 2006;21(1):21-5.

27. Einarson A, Koren G. A survey of women's attitudes concerning healthy lifestyle changes prior to pregnancy. JFAS Int. 2006;4:e2.

28. Morin VI, Mondor M, Wilson RD. Knowledge on periconceptional use of folic acid in women of British Columbia. Fetal Diagn Ther. 2001;16(2):111-5.

29. Coonrod DV, Bruce NC, Malcolm TD, Drachman D, Frey KA. Knowledge and attitudes regarding preconception care in a predominantly low-income Mexican American population. Am J Obstet Gynecol. 2009;200(6):686.

30. Gautan P, Dhakal R. Knowledge on preconception care among reproductive age women. Saudi J Med Pharm Sci. 2016;2(1):6.

31. Al-Akour N, Sou'Ub R, Mohammad K, Zayed F. Awareness of preconception care among women and men: a study from Jordan. J Obstet Gynaecol. 2015;35(3):246-50.

32. Lawal TA, Yusuf B, Fatiregun AA. Knowledge of birth defects among nursing mothers in a developing country. Afr Health Sci. 2015;15(1):180-7.

33. Patabendige $\mathrm{M}, \mathrm{Goonewardene} \mathrm{I.} \mathrm{Preconception} \mathrm{care} \mathrm{received} \mathrm{by}$ women attending antenatal clinics at a Teaching Hospital in Southern Sri Lanka. Sri Lanka J Obstet Gynaecol. 2013;35(1):3-9. 